\title{
ON MAXIMAL AREA INTEGRAL PROBLEM FOR ANALYTIC FUNCTIONS IN THE STARLIKE FAMILY
}

\author{
S. K. SAHOO AND N. L. SHARMA
}

\begin{abstract}
For an analytic function $f$ defined on the unit disk $|z|<1$, let $\Delta(r, f)$ denote the area of the image of the subdisk $|z|<r$ under $f$, where $0<r \leqslant 1$. In 1990, Yamashita conjectured that $\Delta(r, z / f) \leqslant \pi r^{2}$ for convex functions $f$ and it was finally settled in 2013 by Obradović and et. al.. In this paper, we consider a class of analytic functions in the unit disk satisfying the subordination relation $z f^{\prime}(z) / f(z) \prec(1+(1-2 \beta) \alpha z) /(1-\alpha z)$ for $0 \leqslant \beta<1$ and $0<\alpha \leqslant 1$. We prove Yamashita's conjecture problem for functions in this class, which provides a partial solution to an open problem posed by Ponnusamy and Wirths.
\end{abstract}

Mathematics subject classification (2010): Primary 30C45; Secondary 30C55.

Keywords and phrases: Analytic, univalent and starlike functions, subordination, Dirichlet finite, area integral, Parseval-Gutzmer formula, Gaussian hypergeometric functions.

\section{REFERENCES}

[1] M. K. Aouf, Coefficient estimates for some classes of p-valent functions, Int. J. Math. Math. Sci., 11 (1) (1988), 47-54.

[2] J. Cluine, On meromorphic schlicht functions, J. London Math. Soc., 34 (1959), 215-216.

[3] J. G. Clunie And F. R. Keogh, On starlike and convex schlicht functions, J. London Math. Soc., 35 (1960), 229-233.

[4] P. L. Duren, Univalent Functions, Springer-Verlag, New York, 1983.

[5] R. F. Gabriel, The Schwarzian derivative and convex functions, Math. Ann., 6 (1955), 58-66.

[6] A. W. Goodman, Univalent Functions, Vol. 1-2, Mariner, Tampa, Florida, 1983.

[7] W. JANOWS KI, Some extremal problem for certain families of analytic functions, Ann. Polon. Math., 28 (1973), 297-326.

[8] R. J. LiberA, Univalent $\alpha$-spiral functions, Canad. J. Math., 19 (1967), 449-456.

[9] A. MARX, Untersuchungen über schlichte Abbildungen, Math. Ann., 107 (1933), 40-67.

[10] E. P. Merkes, On products of starlike functions, Proc. Amer. Math. Soc., 13 (1962), 960-964.

[11] M. Obradović, S. Ponnusamy, And K.-J. Wirths, A proof of Yamashita's conjecture on area integral, Comput. Methods Funct. Theory, 13 (2013), 479-492.

[12] M. Obradović, S. Ponnusamy, And K.-J. Wirths, Integral means and Dirichlet integral for analytic function, Math. Nachr., 288 (2-3) (2015), 334-342.

[13] K. S. Padmanabhan, On certain classes of starlike functions in the unit disk, J. Indian Math. Soc., (N.S.) 32 (1968), 89-103.

[14] Ch. Pommerenke, Univalent functions, Vandenhoeck and Ruprecht, Göttingen, 1975.

[15] S. PonnusAmy, AND K.-J. Wirths, On the problem of Gromova and Vasil'ev on integral means, and Yamashita's conjecture for spirallike functions, Ann. Acad. Sci. Fenn. Ser. AI Math., 39 (2014), 721-731.

[16] M. S. Robertson, On the theory of univalent functions, Ann. of Math., 37 (2) (1936), 374-408.

[17] M. S. Robertson, Quasi-subordination and coefficient conjectures, Bull. Amer. Math. Soc., 76 (1970), 1-9.

[18] W. Rogosins KI, On the coefficients of subordinate functions, Proc. London Math. Soc., 48 (2) (1943), $48-82$. 
[19] A. SchILD, On a class of univalent, star shaped mappings, Proc. Amer. Math. Soc., 9 (1958), $751-$ 757.

[20] E. Strohacker, Beitrage Zur Theorie Der Schlichten Funktionen, Math. Z., 37 (1933), 356-380.

[21] S. Yamashita, Area and length maxima for univalent functions, Proc. London Math. Soc., 41 (2) (1990), 435-439. 